\title{
Modulation of Islet Immunogenicity Immunoelectron Microscopic Localization of MHC Structures in Isolated Pancreatic Rat Islets
}

\author{
BRITA VON GAUDECKER, KARIN ULRICHS, AND WOLFGANG MÜLLER-RUCHHOLTZ
}

\begin{abstract}
An immunogold-silver enhancement technique, which combines effective labeling of viable isolated islets with the ultrastructural resolution of cytological details, was applied in electron microscopy to identify major histocompatibility complex (MHC) structures on islet cells. Incubation of freshly isolated islets from CAP (RT1') and LEW (RT1') rats with OX18, an MHC class I antibody, showed strong positive reactivity in macrophages and/or dendritic-like cells (M 0 -DCs) and vascular endothelial cells (VEs) and a comparatively weaker reactivity in endocrine $\alpha^{-}, \beta^{-}$, and $\delta^{-c e l l s . ~ W i t h ~}$ MHC class II antibody OX6 (anti-I-A), Mø-DCs were strongly labeled in both rat strains on the surface and on internal structures. Three of five particularly high titered batches of OX6 revealed MHC class II expression on VE and $\beta$-cells. Four days of in vitro culture in combination with a high concentration of glucose and interferon- $\gamma$ induced strong enhancement of MHC class I structures and, to a lesser extent, class II structures on $\beta$-cells. Diabetes 38 (Suppl. 1):150-53, 1989
\end{abstract}

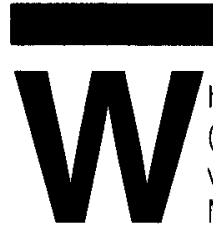

hereas major histocompatibility complex $(\mathrm{MHC})$ class I structures are expressed on a wide range of cell types, the expression of $\mathrm{MHC}$ class II structures, including pancreatic islets, appears to be limited to bone marrow-derived cells (1). However, there is increasing evidence that class II structures can also be expressed on nonlymphoid cells, including islet cells under certain functional conditions (2,3). Because class II molecules are known to play an essential role in the induction of T-lymphocyte-dependent immune responses, their detailed analysis appears to be of great importance for determining the immunogenicity of the future islet graft.

From the Departments of Anatomy and Immunology, Medical School of the University of Kiel, Kiel, FRG.

Address correspondence and reprint requests to Priv. Doz. Dr. Brita von Gaudecker, Department of Anatomy, University of Kiel, Olshausenstrasse 40, D-2300 Kiel, FRG.
Light-microscopic (LM) studies do not allow a precise identification of all islet cell types. Therefore, we applied the immunogold-silver enhancement technique (ISET), which combines effective labeling of viable pancreatic islet cells with the ultrastructural resolution of cytological details, in electron microscopy (EM) to isolated rat islets. In contrast to solid organs, the much smaller islets allowed successful immunolabeling in toto before fixation and embedding.

\section{MATERIALS AND METHODS}

The inbred rat strains CAP (RT1') and LEW (RT1') were bred at the Department of Immunology (Univ. of Kiel) and used at the age of 2-3 mo. Rat islets were isolated according to the technique of Lacy and Kostianovsky (4). Only clean, handpicked islets were used. OX18 (against a monomorphic determinant of the rat $\mathrm{MHC}$ class I molecule; Camon, Wiesbaden, FRG) and OX6 (against a monomorphic I-A determinant of the rat $\mathrm{MHC}$ class II molecule; Camon) were the primary monoclonal antibodies used. Three of five batches of OX6 showed a particularly high avidity for their determinant and were thus called OX6-HT. Antibodies were used in dilutions ranging from $1: 40$ to $1: 80$ in phosphate-buffered saline (PBS). Goat anti-mouse IgG coupled to $5-\mathrm{nm}$ gold particles (dilution 1:5 in PBS; Janssen Life Sciences, Belgium) was used as secondary antibody. Two hundred isolated, handpicked, viable islets were incubated at $24^{\circ} \mathrm{C}$ successively with $200 \mu \mathrm{l}$ diluted primary and secondary antibody for $40 \mathrm{~min}$ each. Islets were subsequently fixed in a mixture of $2 \%$ formaldehyde and $2.5 \%$ glutaraldehyde overnight. After treatment with a silver enhancement solution from Janssen, islets were osmicated and embedded in araldite. Ultrathin sections were evaluated with a Zeiss 902 electron microscope. There were two negative control groups-islets incubated with the nonspecific anti-HLA-DR antibody $1 \mathrm{aB} 3$ and those incubated without the primary antibody. Nonspecific binding of IgG was never observed.

\section{RESULTS}

The EM technique resulted in very good tissue preservation. Silver enhancement of the 5-nm gold particles allowed rapid 
and precise identification of positively reacting cells, particularly at lower magnifications. Ultrathin sections of freshly isolated islets showed a rather loose architecture. Groups of endocrine cells were separated by interstitial spaces containing numerous capillaries and some macrophage and/or dendritic-like cells ( $M \emptyset$-DCs). Occasionally, but very rarely, a lymphocyte or fibrocyte was recognized. The insulin-se- creting $\beta$-cell as predominant cell type comprised $\sim 80 \%$ and the glucagon-secreting $\alpha$-cell $\sim 20 \%$ of the total tissue. $\alpha$-Cells were located mainly in groups or strands along the periphery of the islets. Single somatostatin-secreting $\delta$-cells appeared to be sandwiched between $\alpha$ - and $\beta$-cells at the islet periphery

Reaction pattern with MHC class I antibody OX18. Incu-
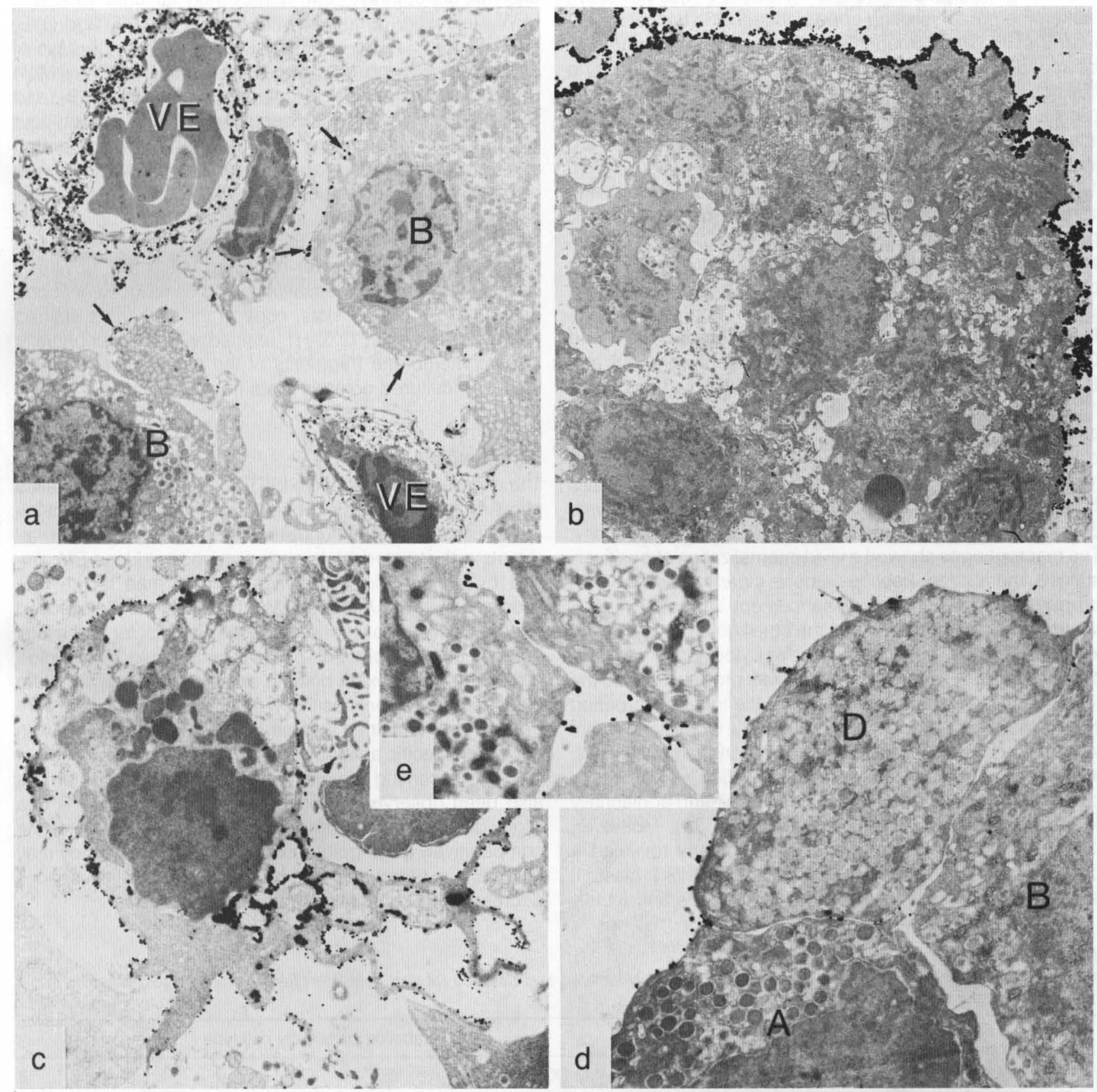

FIG. 1. Isolated LEW islets labeled in toto with immunogold-silver enhancement technique for MHC class I and class II expression. a: Freshly isolated islet incubated with OX6-HT; capillaries (VE) label fairly strongly for class II molecules. In contrast, $\beta$-cells (B) are labeled more weakly and show signs of internalization (arrows) $(\times 5100)$. b: Islet cultured in vitro with OX18 for 4 days in presence of high concentrations of glucose and interferon- $\gamma$. Class I expression is seen only at islet periphery, possibly because of condensation of endocrine cells during in vitro culture. Capillaries and macrophages and dendritic cells are missing $(\times 2400)$. c: Freshly isolated islet incubated with OX6 revealed macrophage with strong class II cell surface reaction and some positive cytoplasmic vacuoles $(\times 7900)$. $d$ : Freshly isolated islet incubated with $0 \times 18$; $\alpha$-cell $(A)$ and $\delta$-cell $(D)$ are weakly labeled for class I molecules; adjacent $\beta$-cell remains unstained. Note different morphologies of secretion granules of $\alpha$ - and $\delta$-cells $(\times 7900)$. e: Freshly isolated islet incubated with high-titer OX6. $\beta$-Cells show dotlike cell surface reactivity for class II molecules. Notice specific $\beta$-cell secretion granules with homogeneous round granule core surrounded by a distinct electron-lucent space $(\times 8800)$. 
bation of CAP and LEW islets with the OX18 antibody showed strong positive cell surface reactivity in $M \phi$-DCs and vascular endothelial cells (VEs). The endocrine cells were labeled comparatively more weakly for MHC class I molecules ( $\alpha-$ cells $>\beta$-cells $=\delta$-cells $)$. $\alpha$-Cell secretion granules $(\sim 300$ $\mathrm{nm}$ diam) were characterized by a clearly demarcated, spherical, extremely electron-opaque core and a small electron-lucent space separating the core from the limiting membrane (Fig. 1d). $\beta$-Cell secretion granules $(\sim 300 \mathrm{~nm}$ diam) lacked the paracrystalline appearance that is typical for human $\beta$-cells. The homogeneous granule core appeared to be round and separated from the limiting membrane by a distinct electron-lucent space (Fig. 1, a and e). Numerous $\beta$-cells contained labeled antibody within cytoplasmic vesicles near the cell surface, indicating internalization during incubation with the secondary, gold-coupled antibody (Fig. 1a). $\delta$-Cells labeled rather weakly with OX18 (Fig. 1d) and very rarely showed internalization. They were characterized by a uniform population of secretory granules homogeneously filled with a moderately electron-opaque mass. Their granules tended to be slightly smaller than $\alpha$ - or $\beta$-cell granules.

Reaction pattern with MHC class II antibodies OX6 and OX6-HT. Incubation of CAP and LEW islets with OX6 and OX6-HT confirmed and extended our earlier findings in immunofluorescence LM (3). The commercially available OX6 antibody, directed against the I-A determinant of the $\mathrm{MHC}$ class II molecule, labeled only M $\emptyset$-DCs and occasionally a lymphocyte in both rat strains (Fig. 1C). Most of these cells had the ultrastructural appearance of macrophages with phagocytic-inclusion bodies of different sizes and density. The macrophages showed a vivid internalization of positively stained membrane fractions, more clearly identifiable in preparations without silver enhancement. At higher magnification it became obvious that the small gold particles were located at the cell surface and also in cytoplasmic vacuoles of varying sizes. This internalization was probably due to the remaining viability of the cells during the incubation period with the gold-coupled secondary antibody. Occasionally, but very rarely, this type of cell resembled nonphagocytic DCs, which lack phagosomes. However, OX6-HTs (i.e., those batches with higher avidity for their determinant) additionally reacted strongly with islet capillaries (Fig. 1a). Moreover, ISET with this highly reactive antibody clearly revealed a dotlike, weak, and cell surface-restricted MHC class II expression on $\beta$-cells as well (Fig. 1e). $\alpha$-Cells and $\delta$-cells were negative. Although the general reaction pattern appeared to be similar in both rat strains, the intensity of reactivity differed by allotype (CAP > LEW; data not shown).

Ultrastructure and $\mathrm{MHC}$ expression of islets after in vitro culture with high concentration of glucose and interferon- $\boldsymbol{\gamma}$ (IFN- $\boldsymbol{\gamma}$ ). It is widely believed that in vitro culture reduces islet immunogenicity and in particular the number of bone marrow-derived cells (5). To evaluate this phenomenon ultrastructurally, EM studies with cultured CAP and LEW islets were performed with the OX18, OX6; and OX6$\mathrm{HT}$ antibodies. Islets were stimulated during the 4 days of culture with $350 \mathrm{mg} / \mathrm{dl}$ glucose and $1.200 \mathrm{U} / \mathrm{ml}$ IFN- $\gamma$. Most of the cultured islets were composed of viable $\alpha-, \beta-$, and $\delta$-cells still containing their secretion granules. Twenty-four hours after in vitro culture, the VE apparently degenerated and had completely disappeared after 4 days. $M \phi$-DCs were also missing in viable islets. With OX18, more $\beta$-cells than $\alpha$-cells of both rat strains showed increased labeling of all membrane fragments that face the islet periphery (Fig. 1b). Cells within the islet center remained unstained, obviously because of tissue condensation, and thus reduced antibody diffusion. In cultured islets, none of the cell types stained with OX6; however, OX6-HT reacted with the peripherally located membrane fragments of the $\beta$-cells more strongly than in uncultured controls (data not shown).

\section{DISCUSSION}

The excellent contrast of the ISET contributes to the detailed ultrastructural analysis of observations made by indirect immunofluorescence/immunoperoxidase LM (1). Earlier attempts with isolated islets and immunoperoxidase EM, limited by nonspecific peroxidase staining, had led to less precise results (6). Although LM with viable total islets proved to be superior to frozen-tissue-section LM insofar as the total number of $\mathrm{MHC}$ class $\|$-positive cells could be counted rapidly $(3,7)$, the exact binding site of the antibody and the ultrastructure of the positively reacting cell type (e.g., endocrine cell) remained unclear despite double staining with cell-type-specific antibodies. The ISET proves to be of great help in overcoming this methodological limitation, which has also been observed by others (2). However, there is one slight disadvantage when incubating a tissue in toto: the comparatively large gold-coupled secondary antibody may not reach its target and thus fail to stain if interstitial spaces decrease, e.g., during in vitro culture (Fig. 1b)

TABLE 1

Major histocompatibility complex reaction pattern of freshly isolated and cultured rat islet cells identified by immunogold-silver enhancement electron microscopy

\begin{tabular}{|c|c|c|c|c|c|c|}
\hline Islet condition & Antibody & \multicolumn{5}{|c|}{ Labeling pattern by cell type } \\
\hline \multirow[t]{2}{*}{ Freshly isolated } & OX18 & +++ & +++ & ++ & + & + \\
\hline & $\mathrm{O} \times 6-\mathrm{HT}$ & ++++ & +++ & - & + & - \\
\hline \multirow[t]{2}{*}{ Cultured (glucose + inferferon) } & $0 \times 18$ & Not identified & Degenerated & ++ & +++ & - \\
\hline & $0 \times 6$ & Not identified & Degenerated & - & - & - \\
\hline
\end{tabular}

Labeling pattern: ++++ , very strong; +++ , strong, ++ , weak; + , very weak; - , negative. M $\phi$-DC, macrophages and dendritic-like cells; VE, vascular endothelial cells; OX6-HT, high-titered batch of OX6. 
The loss of $M \phi-D C s$ and VE in cultured islets confirms comparable data of other authors on rat and mouse islets $(1,6)$. Thus, in vitro culture can be taken as a valuable means of reducing the islet immunogenicity provided by these two cell types. However, in vitro culture with IFN- $\gamma$, a substance known to stimulate MHC molecule expression, increases class I (Fig. 1b) and to a lesser extent class II molecule expression on $\beta$-cells (Table 1; EM data have been confirmed by immunofluorescence $L M$ in unpublished observations). The latter observation, which is being further investigated and quantified with both techniques, $L M$ and $E M$ (ISET), is in some concordance with recent reports from other laboratories (9-11). According to those reports, IFN- $y$ induces rather than increases class II expression. Both modes of $\mathrm{MHC}$ expression could be part of a mechanism controlling the induction of autoimmunity and/or allograft rejection and thus should be further elucidated

\section{ACKNOWLEDGMENTS}

We thank M. Bartels, L. Hoffmann, and M. v. Kolszynski for skillful technical assistance.

This work was supported by Deutsche Forschungsgemeinschaft Grants SFB 111/CN11 and SFB 111/B12-B.

\section{REFERENCES}

1. Faustman D, Hauptfeld V, Davie JM, Lacy PE: Murine pancreatic $\beta$-cells express $\mathrm{H}-2 \mathrm{~K}$ and $\mathrm{H}-2 \mathrm{D}$ but not la antigens. J Exp Med 151:1563-68, 1980

2. Halloran PF, Wadgymar $A$, Autenried $P$ : The regulation of expression of major histocompatibility complex products. Transplantation 41:413-20. 1986

3. Uirichs $K$, Müller-Ruchholtz W: MHC class II antigen expression on the various cells of normal and activated isolated pancreatic islets. Diag Immuno/ 3:47-55, 1985

4. Lacy PE, Kostianovsky M: Method for the isolation of intact islets of Langerhans from the rat pancreas. Diabetes 16:35-39, 1967

5. Lafferty KJ, Prowse SJ, Simeonovic CJ, Warren HS: Immunobiology of tissue transplantation: a return to the passenger leukocyte concept. Annu Rev Immunol 1:143-73, 1983

6. Rabinovitch A, Alejandro R, Noel J, Brunschwig JP, Ryan US: Tissue culture reduces la antigen-bearing cells in rat islets and prolongs islet allograft survival. Diabetes 31 (Suppl. 4):48-54, 1982

7 Gebel HM, Yasunami Y, Diekgraefe B, Davie JM, Lacy PE: la-bearing cells within isolated canine islets. Transplantation $36: 346-48,1983$

8. Parr $\mathrm{EL}$, Bowen KM, Lafferty $\mathrm{KJ}$ : Cellular changes in cultured mouse thyroid glands and islets of Langerhans. Transplantation 30:135-41, 1980

9. Wright JR Jr, Lacy PE, Unanue ER, Muszynski C, Hauptfeld V: Interferonmediated induction of la antigen expression on isolated murine whole islets and dispersed islet cells. Diabetes 35:1174-77, 1986

10. Pujol-Borrell R, Todd I, Doshi M, Bottazzo GF, Sutton R, Gray D, Adolf GR, Feldmann M: HLA class II induction in human islet celis by interferon$\gamma$ plus tumor necrosis lactor or lymphotoxin. Nature (Lond) 326:304-306, 1987

11. Walker R, Cooke A, Bone AJ, Dean BM, van der Meide P, Baird JD: Induction of class II MH-C antigens in vitro on pancreatic $B$ cells from $B B$ / E rats. Diabetologia 29:749-51, 1986 